\title{
Social Support and Condom Use Among Female Sex Workers in China
}

\section{SHAN QIAO,}

Prevention Research Center, Carman and Ann Adams Department of Pediatrics, School of Medicine, Wayne State University, Detroit, Michigan, USA

\section{XIAOMING LI,}

Prevention Research Center, Carman and Ann Adams Department of Pediatrics, School of Medicine, Wayne State University, Detroit, Michigan, USA

\section{CHEN ZHANG,}

Institute of Global Health, University of Vanderbilt, Nashville, Tennessee, USA

\section{YUEJIAO ZHOU,}

Guangxi Center for Disease Control and Prevention, Guangxi, China

ZHIYONG SHEN, and

Guangxi Center for Disease Control and Prevention, Guangxi, China

\section{ZHENZHU TANG}

Guangxi Center for Disease Control and Prevention, Guangxi, China

\begin{abstract}
While the relationship between social support and psychological well-being has been well established, limited studies have explored how social support might affect condom use among female sex workers (FSWs). Using cross-sectional data from 1,022 FSWs in Guangxi, China, we examined how different forms of support from diverse sources may influence condom use among FSWs. Friends, coworkers, and stable partners were FSWs' main sources of social support. Social support from diverse sources differently impacts FSWs' condom use. Policymakers need to consider the complicated profile of social support received by FSWs and create supportive environment for FSWs to protect themselves from HIV risks.
\end{abstract}

By the end of 2011, it was estimated that 780,000 people were living with HIV in China, and the cumulative number of reported deaths due to AIDS reached 93,000 (China Ministry of Health, 2012). Heterosexual transmission has been a primary mode of HIV infection in China. Of the 780,000 people living with HIV, $46.5 \%$ were infected through heterosexual transmission (China Ministry of Health, 2012). Of the estimated 48,000 new infections in 2011, heterosexual transmission accounted for 52.2\% of the cases (China Ministry of Health, 2012). Commercial sex might be one of the key factors that speed the increasing heterosexual transmission in China in recent years (Zhao et al.,2012). The infection

Address correspondence to Shan Qiao, Prevention Research Center, Carman and Ann Adams Department of Pediatrics, School of Medicine, Wayne State University, Hutzel Building, Suite W534, 4707 St. Antoine, Detroit, MI 48201, USA. sqiao@med.wayne.edu. 
transmitted between female sex workers (FSWs) and their clients might result in a rapid spread of the epidemic to the general population (Rojanapithayakorn, 2006).

Commercial sex is illegal in China. It has grown to a widespread industry since the 1980s, however, largely driven by economic disparities and changing sexuality (Hong \& Li, 2008). Estimated numbers of FSWs vary from four million to 10 million depending on different definitions and methods (Tucker et al., 2005). Some estimations count direct FSWs (who earn a living by selling sex and identify themselves as sex workers) or indirect FSWs (who supplement their income by sex work on a regular basis or occasionally), while others count both (Vandepitte et al., 2006). In addition, various methods have been used to identify and enumerate this hidden population including mapping and census, the multiplier method, and capture-recapture (Vuylsteke et al., 2010). In 2011, the overall HIV prevalence among FSWs was $0.3 \%$ (China Ministry of Health, 2012), but the rate of HIV infection among this population was as high as $10.3 \%$ and $16 \%$ in some areas in Yunnan and Guangxi (Wang, Li, Stanton, Zhang, \& Fang, 2010; Wang et al., 2009).

Consistent and correct condom use is one effective method to protect FSWs and their male partners from HIV infection (Zhao, Wang, Fang, Li, \& Stanton, 2008). The rate of condom use among FSWs has been increasing in China. A considerably high proportion of the FSWs, however, still did not use condoms regularly (Cai, Tan, Chen, Richardus, \& deVlas, 2013). The rate of consistent condom use with stable partners ranged from $8 \%$ to $15 \%$, and the rate with clients ranged from $13 \%$ to $54 \%$ (Hong \& $\mathrm{Li}, 2008$ ).

Recently, researchers have explored the association between condom use among FSWs and social or environmental factors including their economic status, their working environment, perceived support from gatekeepers (e.g., managers or owners of the establishments), and social support from other sources (Hong, Fang, Li, Liu, \& Li, 2008; Huang, Henderson, Pan, \& Cohen, 2004; Liao, Schensul, \& Wolffers, 2003; Rogers, Ying, Xin, Fung, \& Kaufman, 2002).

Social support is a complex concept embracing different aspects of supportive relationships between individuals, including the quantity and type of supportive relationships (e.g., sources of the support); the functional content of the support (emotional support, tangible support, or informational support); and the perceived quality of the support (assessment of social support; Green, 1993). Social support has been found to be positively associated with HIV preventive behaviors including condom use among youth and HIV testing and condom use among women (Gaede et al., 2006; Naar-King et al., 2006; Nyamathi, Stein, \& Swanson, 2000; Qiao, Li, \& Stanton, 2014).

Some researchers have examined the relationship between social support and HIV preventive behaviors among FSWs (Dalla, Xia, \& Kennedy, 2003; Dandona et al., 2005; Jana, Basu, Rotheram-Borus, \& Newman, 2004). A lower level of instrumental and emotional support was associated with higher rates of unprotected sex (Dandona et al., 2005), while a higher level of instrumental and emotional support was related to healthenhancing coping strategies (Dalla et al., 2003). Xia and Yang conducted both qualitative and quantitative studies among FSWs in Shanghai, China, highlighting the importance of 
social support from gatekeepers in promoting consistent condom use among FSWs (Xia \& Yang, 2005; Yang \& Xia, 2006). Hong and colleagues, based on their quantitative study in Guangxi, suggested that environmental support among FSWs was positively related to condom use and HIV testing based on their quantitative study in Guangxi (Hong et al., 2008). Among FSWs in Guangdong, laoxiang (women who migrated from the same region) could provide social support in condom use and condom negotiation as well as health seeking (Tucker et al., 2011).

Most of the researchers, however, focused on just one certain source of social support (e.g., gatekeepers, coworkers). It is unclear whether different forms of support from diverse sources may influence HIV preventive behaviors in various ways among FSWs. Using crosssectional data from 1,022 FSWs in Guangxi China, we aimed to (a) describe social support among FSWs in terms of structure (sources and functions of support) and quantity (i.e., cumulative availability of various sources of support); and (b) explore the association between social support from various sources and condom use with clients and stable partners.

\section{METHODS}

\section{Study Sites}

The current study was conducted in Guangxi province in southwest China. Guangxi is ranked second in terms of HIV prevalence and first in terms of newly reported HIV infection cases in China (Guangxi Center for Disease Control and Prevention [CDC], 2009). We selected two cities in Guangxi, City A and City B, as research sites. City A is located in the northeast of Guangxi with a population of 1.34 million including 620,000 urban residents. City B is located on the southern coast of Guangxi with a population of 1.36 million including 550,000 urban residents. Each city is a famous tourist spot, attracting four to 10 million tourists every year. Along with the rapid development of the local economy and tourism in each city, commercial sex has flourished in the two cities. An estimate of 2,000 FSWs have worked in at least 150 commercial sex venues in each city (Hong et al., 2012).

\section{Recruitment and Data Collection Procedure}

We conducted a cross-sectional survey among FSWs in two study sites in April 2009. Participants were recruited from different types of commercial sex venues including nightclubs, saunas, karaoke (KTV), bars, hair salons, massage parlors, mini hotels, restaurants, and streets. The local research team identified commercial sex venues in each city through ethnographic mapping, and then they contacted the owners or gatekeepers of these venues for their permission to conduct research in their venues. FSWs from a total of 56 venues participated in the study. Once we obtained permission from the gatekeepers, research staff from the local CDC approached the FSWs in the venues to ask for their participation. The street-based FSWs were recruited by direct contact or peer referral. About $70 \%$ of the FSWs who were approached agreed to participate in this study. The main reasons for nonparticipation included unavailability and lack of interest in completing the survey. A total of 1,022 FSWs (507 in City A and 515 in City B) provided written informed consent and completed a self-administered questionnaire. Each participant received a small gift with 
a cash value equivalent to 30 Yuan (Chinese currency 1Yuan = U.S. \$0.146 in 2009) as a token of appreciation. To ensure confidentiality of the responses, the survey was conducted in separate rooms or private spaces in the venues/locations where participants were recruited. No one was allowed to stay with the participants during the survey except the interviewer, who provided the participants with necessary assistance. The questionnaire took about 45 minutes to complete. The study protocol was approved by the Institutional Review Boards at Wayne State University in the United States and Beijing Normal University in China.

\section{Measures}

Demographic characteristics.-Demographic information collected in the study included the participants' age, ethnicity, residency (rural or urban), education attainment, marital status, length of time working in the current city (in months), living arrangement (i.e., whether or not lived with a stable partner), and monthly income. For the purpose of data analysis, we categorized ethnicity into Han (a main ethnic group in China, accounts for approximately $92 \%$ of Chinese population) and non-Han (ethnic minorities) and education into less than middle school versus at least middle school. The monthly income was categorized into three levels: low income (less than 1,000 Yuan), middle income (between 1,000 and 2,000 Yuan), and high income (more than 2,000 Yuan).

Perceived social support.-Measurement of perceived social support was developed based on existing literature on social support among FSWs and qualitative data we collected during the formative phase of the study. The perceived social support was measured using a $12 \times 6$ matrix in which FSWs were asked to indicate the perceived availability (yes/no) of six potential sources of support (i.e., gatekeepers, stable partners, clients, coworkers, family, and friends) on each of 12 items measuring three functions of support (i.e., informational support, emotional support, and tangible support). Among the 12 items measuring the functions of support, five items were used to measure informational support (e.g., suggestions about health issues), five items were used to assess emotional support (e.g., emotional comfort), and two items were used to measure tangible support (e.g., financial assistance). The cumulative availability of each potential source of support (e.g., gatekeeper) within each function scale (e.g., informational support) was used as a scale score for that particular social support function. Therefore, each social support function (i.e., informational, emotional, and tangible support) was measured using six scale scores in terms of the sources of the support. The $12 \times 6$ measurement matrix of perceived social support and Cronbach alphas for all the subscales were presented in Table 1.

Intention of consistent condom use.-The intention of future condom use was measured using two questions: "How often will you use condoms with your clients in the future?" and "How often will you use condoms with your stable partners in the future?" (never, occasionally, often, and always). Those FSWs who answered "always" were considered to have the intention to use condoms consistently with their clients or stable partners in the future. 
Consistent condom use.-Consistent condom use with clients and stable partners were measured separately with overall frequency of condom use (never, occasionally, often, and always) during sexual intercourses. Participants who answered "always" were considered consistently using condoms with clients or stable partners.

Proper use of condom.-Proper use of a condom was measured by asking "How often do you or your sexual partners (including stable partners and clients) put on a condom before intercourse" (never, occasionally, often, and always). Participants who responded "always" were considered to use condoms properly.

\section{Data Analysis}

First, we conducted descriptive analysis to illustrate the structure (i.e., functions and sources) of social support. Specifically, responses to individual items of each social support scale were presented in a frequency table, and the subscale scores for each function of support were also calculated. Second, we explored the relationship between social support subscale scores and FSWs' demographic characteristics using analysis of variance (ANOVA) for categorical demographic measures and simple linear regressions for continuous demographic measures. Third, bivariate and multivariate logistic regressions were used to examine the associations between subscale scores and measures of condom use. Demographic variables were controlled in each multivariate analysis. All statistical analyses were performed by the SPSS 16.0.

\section{RESULTS}

\section{Demographic Characteristics}

The FSWs in the current study were 25 years old on average $(S D=6.7)$. Half of them were between 21 and 29 years of age, with $29 \%$ of them younger than 20 years old and nearly $20 \%$ of them were at least 30 . About $84 \%$ of them were of Han ethnicity. More than half of the participants (56\%) were from rural areas. About $60 \%$ of the FSWs did not complete middle school. The majority (72\%) of the participants were single, and $27 \%$ of the participants lived with their stable partners (e.g., boyfriends). The mean length of staying in their current city was 44 months $(S D=36)$, and the mean monthly income was 2,670 Yuan $(S D=2,360)$.

\section{Structure of Social Support}

Table 2 presents participants' responses to 12 items measuring three different functions of social support and mean scores of six subscales for each of the three functions of social support. The FSWs perceived the availability of different functions of social support from various sources. As for informational support, the FSWs believed that they could get general suggestions from their coworkers (42.9\%) and friends (42.3\%), especially the suggestions on health issues (30.3\% from coworkers and 30.6\% from friends), and conflict coping with stable partners (38.1\% from coworkers and $44.6 \%$ from friends). The FSWs perceived getting advice on strategies to deal with clients mainly from their coworkers (50.3\%) and gatekeepers (38.8\%). Friends, families, and coworkers were the main sources of support for FSWs to seek advice regarding marriage and romance. 
As for emotional support, nearly $45 \%$ of the FSWs believed that they could obtain comfort and support from friends and nearly $39 \%$ from stable partners. The majority of them believed that they could turn to their friends and coworkers when they did not feel well or needed to chat or talk about annoying issues. As for tangible support, the FSWs perceived the availability of financial support mainly from their families (35\%), friends (32\%), and stable partners (32\%); and they asked for material support mainly from stable partners $(31 \%)$, friends $(27 \%)$, and families $(25 \%)$.

Coworkers were ranked first as source of informational support (mean $=1.95$, range $0-5$ ), followed by friends (mean $=1.83$ ) and stable partners (mean $=.81)$. The leading sources of emotional support were friends (mean $=2.40$, range $0-5)$, coworkers $($ mean $=1.92)$, and stable partners $($ mean $=1.42)$. The three leading sources of tangible support were stable partners $($ mean $=.62$, range $0-2)$, families $($ mean $=.60)$, and friends $($ mean $=.59)$.

\section{Demographic Correlates of Social Support}

As shown in Table 3, age was negatively associated with FSWs' social support from each source. FSWs of Han ethnicity were more likely to seek support from their stable partners but were less likely to ask for help from their friends compared with non-Han ones. FSWs from the rural areas were more likely to obtain information support and emotional support from their coworkers. The education level of the participants was positively associated with the social support from their friends. FSWs who were not currently married were more likely than the married FSWs to obtain support from their gatekeepers, coworkers, and friends. Living with stable partners was positively associated with social support from stable partners but negatively associated with support from their friends. In addition, FSWs with higher income were more likely to obtain support from coworkers and friends.

\section{Social Support and Condom Use}

Nearly $80 \%$ of the participants intended to use condoms consistently with their clients in the future, while only $26 \%$ of them had such intention with their stable partners. Overall, nearly $34 \%$ of the participants reported consistent condom use with their clients. Only $17 \%$ of the FSWs, however, reported consistent condom use with their stable partners. Around $62 \%$ of the FSWs properly use condoms during sexual intercourse. The multivariate analyses produced three main findings (see Table 4). First, support from gatekeeper and friends were positively associated with condom use. The FSWs with more informational support from gatekeeper reported a higher rate of consistent condom use with stable partners $(\mathrm{aOR}=$ $1.264 ; 95 \% \mathrm{CI}=1.036,1.542$ ). The FSWs with higher emotional support from friends were more likely to use condoms correctly $(\mathrm{aOR}=1.085 ; 95 \% \mathrm{CI}=1.002,1.175)$. Second, social support from clients and stable partners, however, was negatively related to condom use. The FSWs with high informational support from their stable partners reported a low rate of correct condom use $(\mathrm{aOR}=.877 ; 95 \% \mathrm{CI}=.771, .996)$. High emotional support from stable partners and clients was significantly related to a low rate of intention to consistently use condoms with stable partners $(\mathrm{aOR}=.892 ; 95 \% \mathrm{CI}=.808, .985)$ and clients $(\mathrm{aOR}=.552$; $95 \% \mathrm{CI}=.389, .785)$, respectively. Third, tangible support was not significantly predictive of condom use measures among the FSWs. 


\section{DISCUSSION}

We present one of the first efforts to analyze the social support among FSWs in China in terms of structure (source of support and function of support) and quantity, and we examine the relationship between condom use and different functions of social support from various sources. Coworkers were the main source of informational support; friends were a leading source of emotional support; and stable partners were the top source of tangible support. The mean of each subscale score for social support was low given the range of the subscale, implying that FSWs received limited social support in terms of quantity. In addition, we found that different sources of social support might influence condom use behavior in different ways. Emotional support from friends was positively associated with correct condom use, and higher informational support from gatekeepers was significantly related to a higher rate of consistent condom use with stable partners. Support from clients and stable partners was negatively associated with condom use.

It is notable that support from friends was conducive to correct condom use, while support from coworkers of the FSWs did not play a significant role in promoting safer sexual behaviors. This might be explained by the possible homogeneity of FSWs within the same commercial sex venue in terms of condom use, knowledge, and attitudes. The coworkers in the same venues might share similar norms of sexual behaviors and information about HIV prevention. The FSWs' friends, however, might come from outside of the venues with different social or occupational backgrounds (Tucker et al., 2011), and they could provide FSWs with new information and resources. In addition, the participants might have difficulties in developing a mutually supportive relationship with their coworkers because of potential competition for clients among FSWs at the same venue (Busza \& Schunter, 2001). The different influences from friends and coworkers might indicate the necessity to reexamine the optimal strategy for peer-led HIV prevention efforts among FSWs.

Social support from stable partners was negatively associated with practice or intention of condom use. The FSWs who sought emotional support from their stable partners were less likely to consistently use condoms with them. Using condoms may be perceived as a threat to the trust in an intimate relationship (Albert, Warner, \& Hatcher, 1998). Willingness to maintain an emotional intimacy and emotional dependence on stable partners might lead the FSWs to place their emotional needs over the risks of unprotected sex and reduce their ability to negotiate condom use (Zhao et al., 2008). According to a study among impoverished inner-city women in the United States, women with more dependence on men for emotional fulfillment, selfe-steem, and support were more likely to engage in unprotected sex (Sobo, 1995).

We also examined how social support from context-specific sources (e.g., gatekeeper, clients) was associated with perceptions and practice of condom use among FSWs. Informational support from the gatekeeper was positively associated with condom use. This finding was consistent with existing studies on the role of gatekeepers in HIV risk reduction among FSWs. Gatekeepers could promote condom use by providing FSWs with HIV prevention knowledge, condom negotiation skills, and suggestions for dealing with abusive clients (Hong et al., 2008; Urada, Morisky, Pimentel-Simbulan, Silverman, \& Strathdee, 
2012). Informational support from the clients was related to a low rate of consistent condom use. This may be explained by a lack of positive social norms on condom use among the clients of FSWs in China (Yang, Latkin, Luan, \& Nelson, 2010).

The current study has several limitations. First, the cross-sectional study design limits our ability to establish causal interpretations. Second, we need to be cautious to generalize the findings based on data from Guangxi because the FSWs in China are very heterogeneous by their commercial sex practices (Hesketh, Zhang, \& Qiang, 2005). Finally, the scale of social support in the current study measures the functions and sources of social support, but the perceived quality of social support was not available.

Our findings, however, have several implications for HIV prevention among this at-risk population. First, we need to pay attention to FSWs' diverse demographic profiles and provide personalized service in accordance with the structure of the social support among them. For example, older, married FSWs and those with low education attainment generally had a low level of social support. We need to be responsive to the needs of various vulnerable subgroups of FSWs. Second, we suggest engaging gatekeepers and coworkers in HIV prevention interventions because they might be the main sources for informational and emotional support for FSWs. We could train gatekeepers to establish and implement condom use policy, increase their HIV-related knowledge, and enhance their communication skills, condom use skills, as well as condom negotiation skills for them to build up a supportive environment in the venue and provide useful guidance or support to FSWs. We could make efforts to create a positive group norm among coworkers for condom use, particularly for consistent condom use with stable partners.

In addition, we could engage clients and stable partners of FSWs in health education and promotion projects to change their misconceptions of condom use and increase their motivations to reduce HIV risk behavior. Peer norms approving condom use were significantly associated with consistent condom use among clients who visited FSWs with friends (Yang et al., 2010). Therefore, educational materials such as posters, brochures, and comic strips can be designed for clients and partners of FSWs to promote procondom norms. Other evidence-based strategies include providing health education and health service for clients and stable partners of FSWs directly at commercial sex venues (Ghys, EttiegneTraore, \& Anoma, 1997), and conducting condom social marketing and community mobilization among groups that are at high risk of commercial sex involvement (e.g., miners, long-distance truck drivers; Lamptey \& Gayle, 2001).

To incorporate social support into HIV prevention interventions for FSWs, future studies are needed to address several conceptual or methodological issues in this area. First, we need to investigate the role of context-specific or HIV-specific social support among FSWs because it may be more useful than a general measure of support in predicting specific behavioral HIV-related outcomes such as condom use (Darbes \& Lewis, 2005). Second, we need to identify factors that may moderate or mediate the association between social support and behavioral outcomes. For instance, the influence of peer and venue support on condom use might be mediated through motivation and self-efficacy of condom use (Yang et al., 2010). Third, we need further research on the social networks of FSWs to identify crucial 
relationships and potential sources of HIV-specific social support. Since the influence of social support on HIV-related behaviors may vary with social relationships, we need to reexamine the intervention approach based on social support and social network.

\section{CONCLUSION}

In summary, our study demonstrated the low quantity of social support for FSWs and the complexity of social support among the FSWs in terms functions, sources, and influence on their condom use. The use of male condoms were not solely under the control of individual FSWs, but they were largely influenced by multiple contextual and social factors such as economic status, clients, social norms or support in the working environment, and governmental policies (Basuki et al., 2002). In China, most of the establishment-based FSWs were migrants from rural areas with a low educational level (Hong \& Li, 2008). Living a clandestine life away from their families limits their access to support from families and hometowns. Policy-makers need to create a supportive environment for condom possession and condom use among FSWs and provide them with accessible and affordable institutional support and resources to protect them from HIV risks, for example, by decriminalizing condom possession (i.e., do not use condoms as material evidence of commercial sex), providing free condom vending machines in entertainment venues, adapting and promoting $100 \%$ condom use programs, eliminating structural barriers that prevent FSWs from qualified health service, reducing health care costs, and alleviating stigma against FSWs among health care providers.

\section{REFERENCES}

Albert AE, Warner DL, \& Hatcher RA (1998). Facilitating condom use with clients during commercial sex in Nevada's legal brothels. American Journal of Public Health, 88, 643-646. doi:10.2105/AJPH. 88.4.643 [PubMed: 9551009]

Basuki E, Wolffers I, Deville W, Erlaini N, Luhpuri D, Hargono R, ... van Beelen N (2002). Reasons for not using condoms among female sex workers in Indonesia. AIDS Education and Prevention, 14, 102-116. doi:10.1521/aeap.14.2.102.23901 [PubMed: 12000229]

Busza J, \& Schunter BT (2001). From competition to community: Participatory learning and action among young, debt-bonded Vietnamese sex workers in Cambodia. Reproductive Health Matters, 9(17), 72-81. pii/S0968-8080(01)90010-2 [PubMed: 11468849]

Cai R, Tan JG, Chen L, Richardus JH, \& deVlas SJ (2013). Prevalence and risk factors of syphilis infection among female sex workers in Shenzhen, China: An observational study (2009-2012). Tropical Medicine \& International Health, 18, 1531-1538. doi:10.1111/tmi.12204 [PubMed: 24118535]

China Ministry of Health. (2012). 2012 China AIDS response progress report. Beijing, China: Author.

Dalla RL, Xia Y, \& Kennedy H (2003). "Just give them what they want and pray they don't kill you": Street-level sex workers' reports of victimization, personal resources, and coping strategies. Violence Against Women, 9, 1367-1394. doi:10.1177/1077801203255679

Dandona R, Dandona L, Gutierrez JP, Kumar AG, McPherson S, Samuels F, \& Bertozzi SM (2005). High risk of HIV in non-brothel based female sex workers in India. BMC Public Health, 5, 87. doi: 10.1186/1471-2458-5-87 [PubMed: 16111497]

Darbes LA, \& Lewis MA (2005). HIV-specific social support predicts less sexual risk behavior in gay male couples. Health Psychology, 24, 617-622. doi:10.1037/0278-6133.24.6.617 [PubMed: 16287408] 
Gaede BM, Majeke SJ, Modeste RR, Naidoo JR, Titus MJ, \& Uys LR (2006). Social support and health behaviour in women living with HIV in KwaZulu-Natal. Journal of Social Aspects of HIV/ AIDS, 3(1), 362-368. doi:10.1080/17290376.2006.9724862 [PubMed: 17601018]

Ghys P, Ettiegne-Traore V, \& Anoma CK $(1997,10)$. HIV seroincidence and STD prevalence during an intervention study among female sex workers in Abidjan, Cote d' Ivoire. Paper presented at the XII meeting of the International Society of STD Research, Sevilla, Spain.

Green G (1993). Social support and HIV. AIDS Care, 5(1), 87-104. doi:10.1080/09540129308258587 [PubMed: 8461365]

Guangxi Center for Disease Control and Prevention (Guangxi CDC). (2009, 7). Update on HIV/AIDS epidemic in Guangxi. Presented at workshop of NIAAA venue-based HIV and alcohol risk reduction among female sex workers in China, Guangxi.

Hesketh T, Zhang J, \& Qiang DJ (2005). HIV knowledge and risk behaviour of female sex workers in Yunnan Province, China: Potential as bridging groups to the general population. AIDS Care, 17, 958-966. doi:10.1080/09540120500100676 [PubMed: 16176892]

Hong Y, Fang X, Li X, Liu Y, \& Li M (2008). Environmental support and HIV prevention behaviors among female sex workers in China. Sex Transmitted Disease, 35, 662-667. doi:10.1097/OLQ. 0b013e31816b322c

Hong Y, \& Li X (2008). Behavioral studies of female sex workers in China: A literature review and recommendation for future research. AIDS and Behavior, 12, 623-636. doi:10.1007/ s10461-007-9287-7 [PubMed: 17694431]

Hong Y, Zhang C, Li X, Fang X, Lin X, Zhou Y, \& Liu W (2012). HIV testing behaviors among female sex workers in Southwest China. AIDS and Behavior, 16(1), 44-52. doi:10.1007/ s10461-011-9960-8 [PubMed: 21538081]

Huang Y, Henderson GE, Pan S, \& Cohen MS (2004). HIV/AIDS risk among brothel-based female sex workers in China: Assessing the terms, content, and knowledge of sex work. Sex Transmitted Disease, 31, 695-700. doi:10.1097/01.olq.0000143107.06988.ea

Jana S, Basu I, Rotheram-Borus MJ, \& Newman PA (2004). The Sonagachi project: A sustainable community intervention program. AIDS Education and Prevention, 16, 405-414. doi:10.1521/ aeap.16.5.405.48734 [PubMed: 15491952]

Kerrigan D, Telles P, Torres H, Overs C, \& Castle C (2008). Community development and HIV/STIrelated vulnerability among female sex workers in Rio de Janeiro, Brazil. Health Education Research, 23(1), 137-145. doi:10.1093/her/cym011 [PubMed: 17363361]

Lamptey PR, \& Gayle HD (2001). HIV/AIDS prevention and care in resource-constrained settings: A handbook for the design and management of programs. Arlington, VA: Family Health International.

Liao SS, Schensul J, \& Wolffers I (2003). Sex-related health risks and implications for interventions with hospitality women in Hainan, China. AIDS Education and Prevention, 15, 109-121. doi: 10.1521/aeap.15.3.109.23834 [PubMed: 12739788]

Naar-King S, Wright K, Parsons JT, Frey M, Templin T, \& Ondersma S (2006). Transtheoretical model and condom use in HIV-positive youths. Health Psychology, 25, 648-652. doi: 10.1037/0278-6133.25.5.648 [PubMed: 17014283]

Nyamathi AM, Stein JA, \& Swanson JM (2000). Personal, cognitive, behavioral, and demographic predictors of HIV testing and STDs in homeless women. Journal of Behavioral Medicine, 23, 123147. doi:10.1023/A:1005461001094 [PubMed: 10833676]

Qiao S, Li X, \& Stanton B (2014). Social support and HIV-related risk behaviors: A systematic review of global literature. AIDS and Behavior, 18, 419-441. doi:10.1007/s10461-013-0561-6 [PubMed: 23921582]

Rogers SJ, Ying L, Xin YT, Fung K, \& Kaufman J (2002). Reaching and identifying the STD/HIV risk of sex workers in Beijing. AIDS Education and Prevention, 14, 217-227. doi:10.1521/aeap. 14.3.217.23892 [PubMed: 12092924]

Rojanapithayakorn W (2006). The $100 \%$ condom use programme in Asia. Reproductive Health Matters, 14(28), 41-52. PII:S968 -8080(06) 28 270-3 [PubMed: 17101421]

Sobo EJ (1995). Finance, romance, social support, and condom use among impoverished inner-city women. Human Organization, 54, 115-128. 
Tucker JD, Henderson GE, Wang TF, Huang YY, Parish W, Pan SM, ... Cohen MS (2005). Surplus men, sex work, and the spread of HIV in China. AIDS, 19, 539-547. [PubMed: 15802971]

Tucker JD, Peng H, Wang K, Chang H, Zhang SM, Yang LG, \& Yang B (2011). Female sex worker social networks and STI/HIV prevention in South China. PLoS One, 6(9), e24819. doi:10.1371/ journal.pone.0024816 [PubMed: 21949760]

Urada LA, Morisky DE, Pimentel-Simbulan N, Silverman JG, \& Strathdee SA (2012). Condom negotiations among female sex workers in the Philippines: Environmental influences. PLoS One, 7(3). doi:10.1371/journal.pone.0033282

Vandepitte J, Lyerla R, Dallabetta G, Grabbe F, Alary M, \& Buve A (2006). Estimates of the number of female sex workers in different regions of the world. Sex Transmited Disease, 82(Suppl. III), iii18-iii25. doi:10.1136/sti.2006.020081

Vuylsteke B, Vandenhoudt H, Langat L, Semde G, Menten J, Odongo F, ... Laga M (2010). Capturerecapture for estimating the size of the female sex worker population in three cities in Cote d'Ivoire and in Kisumu, western Kenya. Tropical Medicine and International Health, 15, 15371543. doi:10.1111/j.1365-3156.2010.02654.x [PubMed: 21054693]

Wang B, Li X, Stanton B, Zhang L, \& Fang X (2010). Alcohol use, unprotected sex, and sexually transmitted infections among female sex workers in China. Sex Transmitted Disease, 37, 629-636. doi:10.1097/OLQ.0b013e3181e2118a

Wang H, Chen RY, Ding G, Ma Y, Ma J, Jiao JH, ... Wang N (2009). Prevalence and predictors of HIV infection among female sex workers in Kaiyuan City, Yunnan Province, China. International Journal of Infectious Disease, 13, 162-169. doi:10.1016/j.ijid.2008.05.1229

Wong ML, Chan R, Lee J, Koh D, \& Wong C (1996). Controlled evaluation of a behavioral intervention programme on condom use and gonorrhoea incidence among sex workers in Singapore. Health Education Research, 11, 423-432. doi:10.1093/her/11.4.423

Xia G, \& Yang X (2005). Risky sexual behavior among female entertainment workers in China: Implications for HIV/STD prevention intervention. AIDS Education and Prevention, 17, 143-156. doi:10.1521/aeap.17.3.143.62904 [PubMed: 15899752]

Yang C, Latkin C, Luan R, \& Nelson K (2010). Peer norms and consistent condom use with female sex workers among male clients in Sichuan Province, China. Sococial Science \& Medicine, 71, 832839. doi:10.1016/j.socscimed.2010.04.039

Yang X, \& Xia G (2006). Gender, work, and HIV risk: Determinants of risky sexual behavior among female entertainment workers in China. AIDS Education and Prevention, 18, 333-347. doi: 10.1521/aeap.2006.18.4.333 [PubMed: 16961450]

Zhao J, Song F, Ren S, Wang Y, Wang L, Liu W, ... Sun Y (2012). Predictors of condom use behaviors based on the Health Belief Model (HBM) among female sex workers: A cross-sectional study in Hubei Province, China. PLoS One, 7(11), e49542. doi:10.1371/journal.pone.0049542 [PubMed: 23185355]

Zhao R, Wang B, Fang X, Li X, \& Stanton B (2008). Condom use and self-efficacy among female sex workers with steady partners in China. AIDS Care, 20, 782-790. doi: 10.1080/09540120701694030 [PubMed: 18728985] 
TABLE 1

The 12×6 Measurement Matrix of Perceived Social Support Among FSWs

\begin{tabular}{|c|c|c|c|c|c|c|}
\hline \multirow[b]{2}{*}{ Functions of social support } & \multicolumn{6}{|c|}{ Sources of social support } \\
\hline & GK & SP & $\mathbf{C L}$ & CW & FA & $\mathbf{F R}$ \\
\hline \multicolumn{7}{|c|}{ Informational support: Who would you like to ask for advice } \\
\hline \multicolumn{7}{|l|}{ General issues } \\
\hline \multicolumn{7}{|l|}{ Health issues } \\
\hline \multicolumn{7}{|l|}{ Dealing with clients } \\
\hline \multicolumn{7}{|l|}{ Conflicts with stable partners } \\
\hline \multicolumn{7}{|l|}{ Marriage or romances } \\
\hline Cronbach's $a$ & .54 & .64 & .40 & .67 & .57 & .68 \\
\hline \multicolumn{7}{|c|}{ Emotional support: Who would you like to turn to when you } \\
\hline \multicolumn{7}{|l|}{ Need comfort and support } \\
\hline \multicolumn{7}{|l|}{ Need chatting } \\
\hline \multicolumn{7}{|l|}{ Feel uncomfortable } \\
\hline \multicolumn{7}{|l|}{ Miss children and families } \\
\hline \multicolumn{7}{|l|}{ Need talking about annoying } \\
\hline \multicolumn{7}{|l|}{ issues } \\
\hline Cronbach's $a$ & .79 & .79 & .54 & .77 & .66 & .78 \\
\hline \multicolumn{7}{|c|}{ Tangible support: Who would you like to ask for help when you need } \\
\hline \multicolumn{7}{|l|}{ Financial support } \\
\hline \multicolumn{7}{|l|}{ Material support } \\
\hline Cronbach's $a$ & .59 & .72 & .70 & .63 & .61 & .56 \\
\hline Cronbach's $a$ for 12 items & .79 & .86 & .70 & .85 & .79 & .85 \\
\hline
\end{tabular}

Note: $\mathrm{GK}=$ Gatekeepers, $\mathrm{SP}=$ Stable partners, $\mathrm{CL}=$ clients, $\mathrm{CW}=$ Coworkers, $\mathrm{FA}=$ Family members, $\mathrm{FR}=$ Friends . 
TABLE 2

The Structure of Perceived Social Support Among the FSWs in China

\begin{tabular}{lcccccc}
\hline & \multicolumn{7}{c}{ Sources of social support } \\
\cline { 2 - 7 } Functions of social support & GK & SP & CL & CW & FA & FR \\
\hline Informational support $(n=1021, \%)$ & & & & & & \\
$\quad$ General issues & 18.7 & 33.1 & 1.8 & 42.9 & 29.0 & 42.3 \\
Health issues & 6.9 & 25.5 & 1.1 & 30.3 & 26.1 & 30.6 \\
Dealing with clients & 38.8 & 4.8 & 4.6 & 50.3 & 3.4 & 17.5 \\
Conflicts with stable partners & 3.3 & 8.2 & 1.1 & 38.1 & 11.0 & 44.6 \\
Marriage or romances & 4.8 & 9.4 & 1.3 & 33.8 & 34.2 & 48.7 \\
Mean of the sub-scale (0-5) & 0.73 & 0.81 & 0.10 & 1.95 & 1.03 & 1.83 \\
Emotional support $(n=1020, \%)$ & & & & & & \\
Need comfort and support & & & & & & \\
Need chatting & 3.9 & 38.7 & 1.4 & 33.7 & 24.2 & 44.6 \\
When feeling uncomfortable & 5.1 & 29.3 & 3.6 & 51.8 & 20.5 & 59.3 \\
When missing children and families & 3.2 & 25.6 & .9 & 20.1 & 41.5 & 24.2 \\
Need talking about annoying issues & 3.5 & 21.2 & 1.5 & 43.1 & 14.4 & 57.0 \\
Mean of the subscale (0-5) & 0.20 & 1.42 & 0.10 & 1.92 & 1.13 & 2.36 \\
Tangible support $(n=1021, \%)$ & & & & & & \\
Financial support & & & & & & \\
Material support & 7.0 & 31.8 & 4.4 & 20.7 & 34.7 & 32.4 \\
Mean of the subscale (0-2) & 4.9 & 30.6 & 5.0 & 17.4 & 25.4 & 26.6 \\
\hline & 0.12 & 0.62 & 0.10 & 0.38 & 0.60 & 0.59 \\
\hline
\end{tabular}

Note: $\mathrm{GK}=$ Gatekeepers, $\mathrm{SP}=$ Stable partners, $\mathrm{CL}=$ Clients, $\mathrm{CW}=$ Coworkers, $\mathrm{FA}=$ Family members, $\mathrm{FR}=$ Friends . 
TABLE 3

FSW's Demographic Correlates of Their Social Support Structure (Mean of Subscales)

\begin{tabular}{|c|c|c|c|c|c|c|}
\hline \multirow[b]{2}{*}{ Informational support } & \multicolumn{6}{|c|}{ Social support sources } \\
\hline & GK & SP & $\mathrm{Cl}$ & CW & FA & FR \\
\hline $\operatorname{Age}^{*}$ & 0.87 & 0.98 & 0.17 & 2.35 & 1.21 & 2.00 \\
\hline$\geq 20$ & 0.78 & 0.76 & 0.07 & 1.84 & 1.02 & 1.86 \\
\hline $21-29$ & 0.41 & 0.70 & 0.07 & 1.64 & 0.78 & 1.52 \\
\hline \multicolumn{7}{|l|}{$\leq 30$} \\
\hline \multicolumn{7}{|l|}{ Ethnicity } \\
\hline Han & 0.71 & 0.85 & 0.10 & 1.90 & 1.03 & 1.81 \\
\hline Non-Han & 0.86 & $0.62^{*}$ & 0.09 & 2.16 & 1.06 & 1.97 \\
\hline \multicolumn{7}{|l|}{ Residency } \\
\hline Urban & 0.77 & 0.91 & 0.09 & 1.83 & 1.08 & 1.85 \\
\hline Rural & 0.71 & $0.73^{*}$ & 0.11 & $2.04^{*}$ & 1.00 & 1.81 \\
\hline \multicolumn{7}{|l|}{ Education } \\
\hline$<$ Middle school & 0.71 & 0.83 & 0.10 & 1.94 & 1.00 & 1.70 \\
\hline$\searrow$ Middle school & 0.77 & 0.79 & 0.10 & 1.96 & 1.08 & $2.07^{* * *}$ \\
\hline \multicolumn{7}{|l|}{ Marital status } \\
\hline Never & 0.79 & 0.77 & 0.11 & 2.10 & 1.08 & 1.99 \\
\hline Ever & $0.59^{* *}$ & 0.89 & 0.07 & $1.58^{* * *}$ & $0.91^{*}$ & $1.45^{* * *}$ \\
\hline \multicolumn{7}{|l|}{ Living arrangement } \\
\hline Not with partner & 0.75 & 0.64 & 0.10 & 2.00 & 1.04 & 1.90 \\
\hline With partner & 0.68 & $1.25^{* * * *}$ & 0.09 & 1.80 & 1.01 & $1.65^{*}$ \\
\hline \multicolumn{7}{|l|}{ Income levels } \\
\hline Low & 0.59 & 0.76 & 0.08 & 1.70 & 0.98 & 1.61 \\
\hline Middle & 0.74 & 0.90 & 0.09 & 1.85 & 1.07 & 1.98 \\
\hline High & $0.82^{* *}$ & 0.79 & 0.12 & $2.20 * * *$ & 1.05 & $1.91^{* *}$ \\
\hline \multicolumn{7}{|l|}{ Emotional support } \\
\hline \multicolumn{7}{|l|}{$\mathrm{Age}^{*}$} \\
\hline 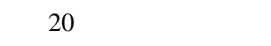 & 0.25 & 1.82 & 0.17 & 2.30 & 1.30 & 2.58 \\
\hline $21-29$ & 0.21 & 1.33 & 0.07 & 1.77 & 1.08 & 2.40 \\
\hline 230 & 0.12 & 1.11 & 0.08 & 1.77 & 1.03 & 1.92 \\
\hline \multicolumn{7}{|l|}{ Ethnicity } \\
\hline Han & 0.20 & 1.48 & 0.10 & 1.88 & 1.12 & 2.30 \\
\hline Non-Han & 0.19 & $1.17^{*}$ & 0.11 & 2.07 & 1.23 & $2.64^{*}$ \\
\hline \multicolumn{7}{|l|}{ Residency } \\
\hline Urban & 0.21 & 1.56 & 0.08 & 1.74 & 1.15 & 2.37 \\
\hline Rural & 0.20 & $1.31^{*}$ & 0.11 & $2.04^{*}$ & 1.12 & 2.34 \\
\hline \multicolumn{7}{|l|}{ Education } \\
\hline$<$ Middle school & 0.20 & 1.44 & 0.09 & 1.98 & 1.12 & 2.22 \\
\hline
\end{tabular}

Health Care Women Int. Author manuscript; available in PMC 2018 November 13. 


\begin{tabular}{|c|c|c|c|c|c|c|}
\hline \multirow[b]{2}{*}{ Informational support } & \multicolumn{6}{|c|}{ Social support sources } \\
\hline & GK & SP & Cl & CW & FA & FR \\
\hline$\unrhd$ Middle school & 0.21 & 1.40 & 0.10 & 1.80 & 1.16 & $2.60^{* *}$ \\
\hline \multicolumn{7}{|l|}{ Marital status } \\
\hline Never & 0.22 & 1.44 & 0.11 & 2.00 & 1.18 & 2.56 \\
\hline Ever & 0.15 & 1.37 & 0.08 & $1.72 *$ & 1.05 & $1.88^{* * *}$ \\
\hline \multicolumn{7}{|l|}{ Living arrangement } \\
\hline Not with partner & 0.23 & 1.18 & 0.11 & 1.95 & 1.17 & 2.42 \\
\hline With partner & $0.12 *$ & $2.09^{* * * *}$ & 0.07 & 1.84 & 1.05 & $2.17^{*}$ \\
\hline \multicolumn{7}{|l|}{ Income levels } \\
\hline Low & 0.20 & 1.24 & 0.07 & 1.73 & 1.03 & 2.06 \\
\hline Middle & 0.18 & 1.62 & 0.09 & 1.84 & 1.20 & 2.55 \\
\hline High & 0.22 & $1.43^{*}$ & 0.12 & $2.11^{*}$ & 1.17 & $2.43^{* *}$ \\
\hline \multicolumn{7}{|l|}{ Tangible support } \\
\hline \multicolumn{7}{|l|}{$\mathrm{Age}^{*}$} \\
\hline$\underline{20}$ & 0.19 & 0.69 & 0.87 & 0.98 & 0.17 & 2.35 \\
\hline $21-29$ & 0.10 & 0.62 & 0.78 & 0.76 & 0.07 & 1.84 \\
\hline 230 & 0.05 & 0.54 & 0.41 & 0.70 & 0.07 & 1.64 \\
\hline \multicolumn{7}{|l|}{ Ethnicity } \\
\hline Han & 0.11 & 0.64 & 0.09 & 0.37 & 0.59 & 0.56 \\
\hline Non-Han & 0.15 & 0.52 & 0.10 & 0.44 & 0.64 & 0.74 \\
\hline \multicolumn{7}{|l|}{ Residency } \\
\hline Urban & 0.09 & 0.64 & 0.12 & 0.34 & 0.59 & 0.58 \\
\hline Rural & 0.14 & 0.60 & 0.08 & 0.41 & 0.61 & 0.60 \\
\hline \multicolumn{7}{|l|}{ Education } \\
\hline <Middle school & 0.12 & 0.64 & 0.07 & 0.36 & 0.57 & 0.57 \\
\hline$\geq$ Middle school & 0.10 & 0.60 & $0.14^{* *}$ & 0.41 & 0.64 & 0.63 \\
\hline \multicolumn{7}{|l|}{ Marital status } \\
\hline Never & 0.14 & 0.64 & 0.10 & 0.42 & 0.62 & 0.64 \\
\hline Ever & $0.07^{* *}$ & 0.58 & 0.08 & $0.29^{* *}$ & 0.56 & $0.46^{* * * *}$ \\
\hline \multicolumn{7}{|l|}{ Living arrangement } \\
\hline Not with partner & 0.13 & 0.53 & 0.09 & 0.41 & 0.60 & 0.64 \\
\hline With partner & 0.09 & $0.86^{* * *}$ & 0.11 & $0.30 *$ & 0.60 & $0.46^{* *}$ \\
\hline \multicolumn{7}{|l|}{ Income levels } \\
\hline Low & 0.12 & 0.59 & 0.05 & 0.32 & 0.59 & 0.51 \\
\hline Middle & 0.13 & 0.66 & 0.09 & 0.35 & 0.62 & 0.62 \\
\hline High & 0.11 & 0.63 & $0.13^{*}$ & $0.45^{*}$ & 0.59 & 0.63 \\
\hline
\end{tabular}

Note: $\mathrm{GK}=$ Gatekeepers, $\mathrm{SP}=$ Stable partners, $\mathrm{CL}=$ Clients, $\mathrm{CW}=$ Coworkers, FA = Family members, FR = Friends. Length of living in the city and monthly income were not included in this table since they were not significantly associated with social support. Age was significantly associated with all the variables of social support except emotional support from gatekeepers, tangible support from stable partners, and tangible support from clients.

F-test $p<.05$, 


$* * * 0.01$
$* * *$
$p<.001$.




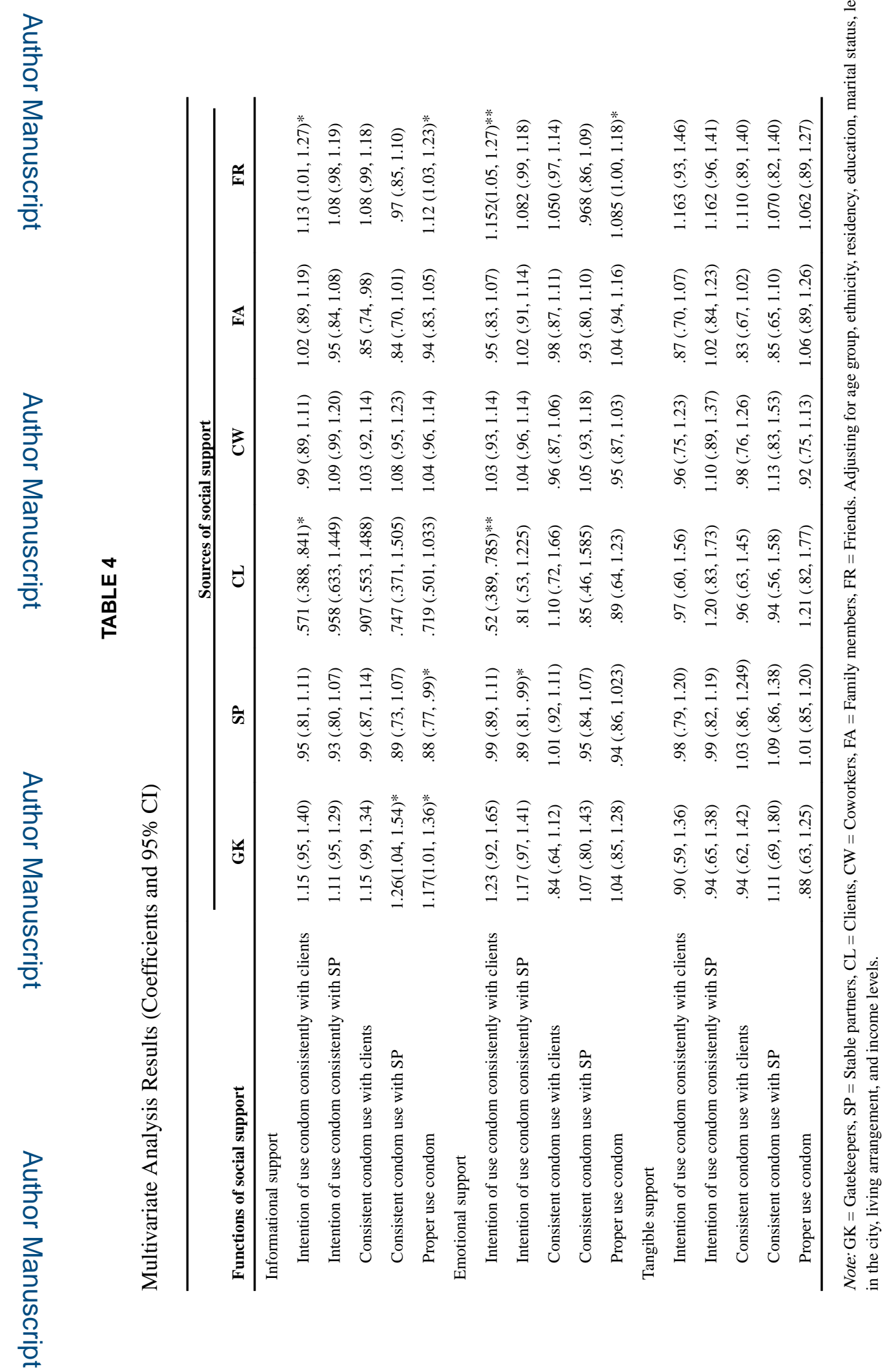

Health Care Women Int. Author manuscript; available in PMC 2018 November 13. 